\title{
Central Asian geo-relation networks: Evolution and driving forces
}

\author{
WANG Yun ${ }^{1,2,3},{ }^{*}$ LIU Yi ${ }^{1,2,3}$
}

1. Key Laboratory of Regional Sustainable Development Modeling, Institute of Geographic Sciences and Natural Resources Research, CAS, Beijing 100101, China;

2. College of Resources and Environment, University of Chinese Academy of Sciences, Beijing 100049, China;

3. Institute of Strategy Research for the Guangdong-Hong Kong-Macao Greater Bay Area, Guangzhou 510070, China

\begin{abstract}
Due to the unique geographical location and historical background of Central Asia, the region's geo-relation networks are complex and changeable. A social network analysis was conducted in this study to visualize the 20-year evolutionary process of bilateral (diplomatic relations) and multilateral (intergovernmental organization (IGO) connections) networks in Central Asia since 1993. Additionally, a further empirical study determined the significant driving forces of the construction of the geo-relation networks. The results showed that since the independence of the five Central Asian countries, their degree centrality $\left(C_{D}^{\prime}\left(n_{i}\right)\right)$ values have been increasing, with the index values being the highest for Kazakhstan, followed by Uzbekistan, while the other three countries had relatively low values. The Central Asian countries maintain bilateral relations with post-Soviet nations, neighboring countries, and Western powers, and have gradually deepened and expanded their diplomatic networks. From each state's perspective, the geostrategic approaches adopted by the five countries were different. Kazakhstan has focused on expanding its bilateral and multilateral relations, while the other Central Asian countries have attempted to increase their influence by joining influential IGOs. Various driving forces, including economic, political, cultural, and geographical factors, have played significant roles in the construction of geo-relation networks in Central Asia. The importance of these factors has changed over time, from political and cultural factors (before 1995) to relations with neighboring countries (1996-2001), and finally to economic power and cultural and religious proximity (after 2002).
\end{abstract}

Keywords: Central Asia; social network analysis; geo-relations; evolution; driving forces

\section{Introduction}

After the collapse of the Soviet Union in December 1991, Kazakhstan, Kyrgyzstan, Tajikistan, Turkmenistan, and Uzbekistan emerged as five newly independent states in Central

Received: 2020-03-21 Accepted: 2020-07-27

Foundation: The Strategic Priority Research of the CAS, No.XDA20040400; National Natural Science Foundation of China, No.41871118

Author: Wang Yun (1993-), PhD Candidate, specialized in geopolitics and regional development.

E-mail: wangyun.16b@igsnrr.ac.cn

*Corresponding author: Liu Yi (1957-), Professor, E-mail: liuy@igsnrr.ac.cn 
Asia. Historically, Central Asia has always had a passive position in international relations, struggling in the whirlpool of the empire-competing game and failing to become a real regional power (Hopkirk, 1992). In contrast, after the collapse of the Soviet Union, the independence of the Central Asian countries resulted in the region becoming an independent geopolitical entity, and it is no longer a "passive recipient, but a decisive player" in the great power competition. The Central Asian countries have gradually established their geopolitical relations in line with their national conditions, which has provided a unique opportunity to examine the evolution of the geopolitical relations and strategies in newly independent states surrounded by great powers.

Because the new political entity is still relatively weak and its historical path dependence has not been overcome, external forces have inevitably had a significant influence on the development of Central Asia. Both its particular geographical location and the abundance of oil and gas resources in Central Asia have further enhanced its strategic position (Jing et al., 2020; Liu et al., 2018). Competition and cooperation between big powers, such as Russia, the United States (U.S.), Europe, China, Japan, India, Iran, and Turkey, are commonly thought to be long-term (Cooley, 2012). Despite its location in the heart of Eurasia, Central Asia is still a fragmented region, where the complexity and variability of geo-relations caused by multiple factors is a prominent feature.

As mentioned above, the study of Central Asian geopolitics cannot be separated from the region's relationships with external powers. A social network analysis is a set of methods that focuses on the "relationships" among social entities, as well as their patterns and implications (Wasserman and Faust, 1994). Many researchers have used such networks to quantify the economic, political, or social structure of the environment. In the field of geopolitics and international relations, a social network analysis is mainly used to discover the structure or attributes of relationships between different individuals, groups, or societies (Hämmerli et $a l ., 2006$ ), and special attention is given to the impacts of the nodes in the network (Maoz et al., 2005; Hafner-Burton et al., 2009). Network analyses are also widely applied to analyze international economics (trade and finance) networks (Smith and White, 1992; Schweitzer et al., 2009). However, the fact that Central Asia has operated as an independent actor in contemporary history is either ignored by most researchers or misinterpreted from the viewpoint of the great powers. How does Central Asia build and evolve its geopolitical relations as a newly independent, but peripheral region in the world's geopolitical network? How does the region intend to orientate itself in the global geopolitical network? Thus, it is meaningful to evaluate the process by which the region has constructed its geopolitical network and identify the main driving factors that have shaped its geo-relations.

\section{Methodology and data}

\subsection{Study area}

This study focused on five Central Asian countries that obtained their independence in 1991, becoming the five sovereign nations of Kazakhstan, Uzbekistan, Kyrgyzstan, Turkmenistan, and Tajikistan. 


\subsection{Social network analysis}

To analyze the geopolitical relations, we focused on two sources of data: international diplomatic relations and membership of intergovernmental organizations (IGOs). For these five newly independent countries in the early 1990s, it is essential to track their progress in establishing an "international social network." Diplomatic relations and membership of IGOs are commonly-adopted approaches to the development of bilateral and multilateral relations (Sandschneider, 2002; Zawahri and Mitchell, 2011; Kinne, 2013).

From a database of embassies, we obtained a matrix $\mathrm{X}$ for each year we studied, indicating the bilateral relationships between the countries:

$$
\begin{gathered}
x_{i j}=w_{e} \sum_{e} e_{i j} \\
w_{e}=y_{e}+1
\end{gathered}
$$

where $x_{i j}$ represents the bilateral relationship between country $i$ and country $j$, while $e_{i j}=1$ if country $i$ and country $j$ have embassies in either country $i$ or $j$ (i.e., country $i$ has embassies in country $j$, country $j$ has embassies in country $i$, or countries $i$ and $j$ set up embassies in each other's territory). We used a standardized $w_{e}$ to weight the embassy, in which $y_{e}$ represents the year that the embassies were established.

The process of building matrixes of IGO connections was more complicated. From the database of IGO membership, we obtained a 2-mode data matrix P, in which $x_{i k}=1$ if country $i$ belongs to IGO $k$. Furthermore, the weights of each IGO were calculated by counting the number of mentions in two politically-focused news databases, the Foreign Broadcast Information Service and the World News Connection. The weights were applied to measure the relative prominence of each IGO. The operation of an IGO enables every member to be aware of each other, obtain consensus, and promote their hierarchical influences on the world. Therefore, an IGO network was obtained by constructing a 1-mode matrix A:

$$
a_{i j}=w_{k} \sum_{k} x_{i k} x_{j k}
$$

where $a_{i j}$ is the product of IGO quantity, where country $i$ and country $j$ are both members of IGO $k$ and the formula also accounts for its weight. We can regard $a_{i j}$ as a proxy for the IGO connection proximity of countries $i$ and $j$, or as a rough indicator of the potential for information flow and shared national interests between them. The weight of an IGO was coded by the dataset, ranging from a minimum of 0 to a maximum observed value of 86.51 in 1993 for the United Nations (UN). The mean IGO weight for the whole period was 3.21 (SD = 9.17), while the median value was 0.01 during the same time frame.

After building the matrix, we used the social network analyzing software Ucinet and Arcmap to visualize the network. The aim was to determine the characteristics of Central Asian countries in the network, with the degree centrality index spanning the period from 1993 to 2013. We selected five years (1993, 1995, 2001, 2008, and 2013), which were deemed to be the turning points of Central Asian geopolitical strategies in previous studies (Kubicek, 1997; Cooley, 2008; Cooley, 2012). Before 1995, the Central Asian nations were still in the early stages of becoming independent sovereignties, during which international recognition was the main objective of the five "stans". At this stage, Russia continued to play an important role in this area, and the U.S. had not formed an overall policy toward 
Central Asia, but adopted the "nuclear non-proliferation strategy" to push forward the denuclearization of Central Asia. From 1996 to 2000, Central Asian countries continued to seek reliable strategic forces and cooperative partners under the premise of ensuring sovereignty, independence, and territorial integrity. At this stage, the U.S. devised an initial policy toward Central Asia, giving a higher priority to political and economic cooperation than military presence. From 2001 to 2008, the Central Asian countries took advantage of the strategic intentions of the great powers to maximize their interests. After the 9-11 terrorist attacks, the U.S. devised a series of strategies to establish a military presence in Central Asia, and competed for the dominant military role. The successive color revolutions revealed a growing zero-distance competition among the great powers in Central Asia. China and Russia played an active part in the establishment of the Shanghai Cooperation Organization (SCO), with the aim of building a new security interaction platform. After 2008, Central Asia's balanced diplomacy became more beneficial and practical. Influenced by the situation in Afghanistan, the U.S. established the "New Silk Road Project," a new integrated strategy for Central Asia.

Degree centrality assigns an importance score based purely on the number of links held by each node, from which we were able to construct a network to establish the progress of Central Asian countries. The degree centrality for diplomatic relations and IGO connections were:

$$
\begin{gathered}
C_{D}\left(n_{i}\right)=d\left(n_{i}\right)=\sum_{j=1}^{g} x_{i j} \\
C_{I G O}\left(n_{i}\right)=D\left(n_{i}\right)=\sum_{j=1}^{g} a_{i j}
\end{gathered}
$$

where $C_{D}\left(n_{i}\right)$ and $C_{I G O}\left(n_{i}\right)$ represent the degree centrality of node $i$ in a diplomatic network or IGO network, respectively. $x_{i j}=1$ when nodes $i$ and $j$ have a connection. The node degree centrality measured this way not only reflects the relevance of each node to other nodes, but also depends on the network size (g). Therefore, the more extensive the network, the higher the maximum possible value of degree centrality. To eliminate the influence of network size changes on degree centrality, a standardized measurement formula was proposed:

$$
\begin{gathered}
C^{\prime}{ }_{D}\left(n_{i}\right)=\frac{d\left(n_{i}\right)}{g-1} * 100 \% \\
C^{\prime}{ }_{I G O}\left(n_{i}\right)=\frac{D\left(n_{i}\right)}{g-1} * 100 \%
\end{gathered}
$$

In this standardized degree centrality measurement formula, the degree centrality value of node $i$ is divided by the maximum possible connections of the other $g-1$ nodes to obtain the proportion of network nodes directly related to node $i$. The scale ranges from 0.0 to 1.0 , where 0.0 means that there is no connection to any node (such as a solitary point), and 1.0 means that there is a direct connection to each node. In social networks, the standardized degree centrality measures an actor's participation in the whole network.

The CONCOR procedure can provide a partitioned network by splitting blocks according to the convergence of iterated correlations (CONCOR). Given an adjacency matrix, or a set of adjacency matrices for different relations, a correlation matrix can be formed by the following procedure. A profile vector is formed by concatenating the row in every adjacency 
matrix. The $i, j$ th element of the correlation matrix is the Pearson correlation coefficient of the profile vectors of $i$ and $j$. This (square, symmetric) matrix is called the first correlation matrix. The procedure can be performed iteratively on the correlation matrix until convergence. Each entry is now 1 or -1 . This matrix splits the data into two blocks, such that members of the same block are positively correlated, while members of different blocks are negatively correlated.

\subsection{Empirical analysis}

\subsubsection{Hypothesis}

What are the characteristics of specific countries that would encourage the Central Asian countries to establish diplomatic relations with them? What are the factors considered by Central Asian countries when they engage in diplomatic activities? Based on various theoretical approaches, the key factors encouraging a country to establish geopolitical relationships have been widely discussed (Huskey, 2008; Pirro, 2015), and they mainly consist of four aspects: economic strength, political and cultural nature, military power, and geographical location.

(1) The relationship between economic power and a country's degree of importance in the Central Asian geopolitical network.

Economic power has a significant influence on geopolitical relationships. Political rights can be established through a comparison of economic strength (Nye, 2008). Weak economies have less bargaining power, and as a result they may make concessions in bilateral and multilateral geopolitical relations. China is often used as an example of this due to its administrative capacities to negotiate through its significant market size and economic power. There are some policy debates regarding economic relations with China, in which it is realistic to assume that China will benefit disproportionately from international trade and the huge augmentation of Chinese power (Bayne and Woolcock, 2011).

Additionally, because economic conditions are a central component of any state's foreign policy, countries actively or passively seek good relations with major economies and use economic instruments in their foreign policies. Kazakhstan's Foreign Policy Concept (http://www.akorda.kz/en/legal_acts/decrees/on-the-concept-of-the-foreign-policy-of-the-rep ublic-of-kazakhstan-for-2020-2030) used the expansion of international cooperation in the priority sectors of the national economy as a means to attract investment and advanced technologies. It is therefore apparent that foreign relations with the leading economic powers are a significant concern for Kazakhstan, which is also the case for other countries that desire to increase their security and competitiveness in the world.

H1: A country's degree of importance in the Central Asian geopolitical network is positively associated with its economic power.

(2) The relationship between the political-cultural features of a country and its degree of importance in the Central Asian geopolitical network.

The Central Asian region was part of the Soviet Union during the Cold War, after which all five countries joined the Commonwealth of Independent States (CIS). Their relations with Russia and other post-Soviet countries were considered diplomatic priorities. As written in Uzbekistan's official foreign policy, “Another priority direction of the foreign policy of Uzbekistan is the CIS member states, with which the country has historically formed po- 
litical, economic, transport-communication, and other ties." With the collapse of the Soviet Union, The North Atlantic Treaty Organization (NATO) membership provides another opportunity for Central Asian countries to form balanced and multidimensional strategic partnerships with some of the world's leading states and international organizations. During the Cold War, NATO represented a Western military alliance against the Soviet Union. Although the Cold War has now ended, NATO still provides the role of a "security provider," representing the interests of the Western world. Various diplomatic strategies are now adopted by Central Asian countries, e.g., the balancing strategy adopted by Kazakhstan, the equilibrium strategy that maximizes the interest adopted by Uzbekistan, the neutralism adopted by Turkmenistan and Kyrgyzstan, and an alliance with Russia adopted by Tajikistan. Through consideration of these diplomatic strategies, we attempted to understand the political tendency of the Central Asian countries as a whole since their establishment.

H2a: A country's degree of importance in the Central Asian geopolitical network is positively associated with its identity as a post-Soviet state.

H2b: A country's degree of importance in the Central Asian geopolitical network is positively associated with its membership of NATO.

(3) The relationship between cultural proximity and a country's degree of importance in the Central Asian geopolitical network.

Huntington (1996) suggested that cultural attributes are essential factors affecting state-to-state relations. A country or a state will carefully consider the other side's cultural nature when it comes to establishing diplomatic relations with it. Central Asia is part of the Islamic civilization, which originated in the Arabian Peninsula in the seventh century A.D., and extended eastward into Central Asia in the eighth century A.D. Ancient Central Asia has since developed an extensive Islamic civilization. Seventy years of Soviet rule in Central Asia did not crush Islam, but it had a profound effect on secularizing society and political elites. Nevertheless, after independence, there was a surge of interest in Islam, including the emergence of Islamist political groups seeking to challenge the secular nature of these new states (Gross, 1992). We were interested in how important relations with Islamic countries are for the five countries of Central Asia. Is religion a real factor that shapes Central Asia's geopolitical network?

H3: A country's degree of importance in the Central Asian geopolitical network is positively associated with its membership of the Organization of Islamic Cooperation (OIC).

(4) The relationship between military power and a country's degree of importance in the Central Asian geopolitical network.

Political unrest, radicalization, terrorism, and drugs supplied from Afghanistan could have a serious impact on the survival of Central Asian governments (de Haas, 2016). With less than 30 years of history as modern countries, the nations of Central Asia are likely to seek national security by supporting, accepting, or investing in existing regimes, i.e., international and regional cooperation. Immediately following the 9-11 terrorist attacks, the U.S. moved quickly to establish a military presence in Uzbekistan and Kyrgyzstan. Russia has operated military bases in some Central Asian countries for decades. The great powers have a distinct military presence in this region, suggesting that military power may play an important role in Central Asia's geopolitical network.

Because we cannot directly observe decision-making in Central Asian countries, it is dif- 
ficult to fully understand how much military concern there is when Central Asian countries engage with Russia, the U.S.-led West, and other parts of the world. Nevertheless, international cooperation and dependence on military powers have played essential roles in the foreign policy and national practices of Central Asian countries.

H4: A country's degree of importance in the Central Asian geopolitical network is positively associated with its military expanse (expenditure).

(5) The relationship between geographical factors and a country's degree of importance in the Central Asian geopolitical network.

Distance, boundaries, and location are the geographical factors that cannot be ignored, because they imply the possibilities and constraints for a country's geo-strategies ( $\mathrm{Li}$ and Long, 2014; Hu et al., 2018). Scholars of geopolitics believe that political and other power is thought to "decay" with increasing distance, although the size of countries can modify this assumed attenuation of influence (Henrikson, 2002). A boundary, which is described as "the most palpable political geographic phenomenon" (Minghi, 1963), relates to the topological relationships among countries, in which the configuration of the political map is the critical variable. Considering the elements mentioned above, geopolitics, especially traditional geopolitics, always emphasizes that "geography matters" (Yang et al., 2015; Song et al., 2017; Zhang et al., 2018).

From a geographical perspective, Central Asia is located in the heart of Eurasia, far from the ocean. The properties of landlocked countries lead to them being treated as diplomatic priorities by their neighboring countries. At the same time, strengthening ties with the outside world is also a diplomatic option. Thus, we attempted to verify whether geographical factors shaped the geopolitical relations of the Central Asian countries.

H5a: A country's degree of importance in the Central Asian geopolitical network is negatively associated with its distance between the two countries.

H5b: A country's degree of importance in the Central Asian geopolitical network is positively associated with its presence as a neighboring country.

\subsubsection{Models and data}

To determine the factors that shape the geopolitical network of Central Asian countries, we constructed the following regression model:

$$
I C A N=\alpha+\beta_{1} G D P+\beta_{2} P S+\beta_{3} N A T O+\beta_{4} O I C+\beta_{5} M E+\beta_{6} D S+\beta_{7} N C+\varepsilon_{i t}
$$

The data were transformed into natural logarithms because we expected non-linearities in the relationships based on theory and previous empirical work.

Our hypotheses, the proxies we used, and the expected signs are detailed in Table 1, together with our data sources. Our dependent variable, i.e., a country's degree of importance in the geopolitical network of Central Asian countries, was proxied by the length of time over which formal diplomatic relations with the Central Asian countries had been established. The larger the value of the dependent variable was, i.e., the longer that the two countries had established diplomatic ties, the more likely they would establish diplomatic relations. For the five Central Asian countries that became newly independent in the 1990s, the sequence in which they established diplomatic relations was indicative of that country's geopolitical importance. Therefore, we used data regarding the date of establishment of embassies inside and outside each country to represent the establishment of formal diplomatic 
relations. The data were obtained from the Diplomatic Dashboard (http://diplodash.pardee. du.edu/) database, which is an interactive web tool for visualizing and analyzing bilateral and multilateral diplomatic connections between countries from 1960 to 2015 (data are available until 2013 in the dataset). As independent variables, proxies such as GDP, membership of political groups, military expenditure, geographical distance, and neighboring countries were selected to test the five hypotheses. We expected the distinctive nature of the factors influencing the network of Central Asian countries to be captured by the collective significance of the main variables that we identified in the table. The data for the independent variables were obtained from open databases.

Table 1 The determinants of a country's degree of importance in the Central Asian geopolitical network

\begin{tabular}{|c|c|c|c|}
\hline Hypotheses and number & Proxy & Expected sign & Data source \\
\hline $\begin{array}{l}\text { A country's degree of importance in } \\
\text { the Central Asian geopolitical net- } \\
\text { work (dependent variable) }\end{array}$ & $\begin{array}{l}\text { ICAN: The length of time over which } \\
\text { formal diplomatic relations have been } \\
\text { established with a Central Asian country }\end{array}$ & + & $\begin{array}{l}\text { Diplomatic Dash- } \\
\text { board }\end{array}$ \\
\hline Economic power $(\mathrm{H} 1)$ & $\begin{array}{l}\text { GDP: the country's GDP in the year } \\
\text { when it established diplomatic relations } \\
\text { with Central Asian countries }\end{array}$ & + & $\begin{array}{l}\text { World Bank de- } \\
\text { velopment indica- } \\
\text { tor }\end{array}$ \\
\hline Identity as a post-Soviet state $(\mathrm{H} 2 \mathrm{a})$ & $\begin{array}{l}\text { PS: }=1 \text { when the country is a post-Soviet } \\
\text { state }\end{array}$ & + & 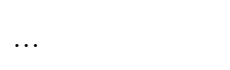 \\
\hline Membership of NATO (H2b) & $\begin{array}{l}\text { NATO: }=1 \text { when the country is a mem- } \\
\text { ber of NATO }\end{array}$ & + & $\begin{array}{l}\text { Official NATO } \\
\text { website }\end{array}$ \\
\hline Membership of OIC(H3) & $\begin{array}{l}\text { OIC: }=1 \text { when the country is a member } \\
\text { of the OIC }\end{array}$ & + & $\begin{array}{l}\text { Official OIC web- } \\
\text { site }\end{array}$ \\
\hline Military power $(\mathrm{H} 4)$ & $\begin{array}{l}\text { ME: the country's military expenditure in } \\
\text { the year when it established diplomatic } \\
\text { relations with Central Asian countries }\end{array}$ & + & $\begin{array}{l}\text { World Bank de- } \\
\text { velopment indica- } \\
\text { tor }\end{array}$ \\
\hline Distance (H5a) & $\begin{array}{l}\text { DS: the geographical distance between } \\
\text { the two capitals }\end{array}$ & - & $\begin{array}{l}\text { The GeoDist Data- } \\
\text { base }\end{array}$ \\
\hline Neighboring country (H5b) & $\begin{array}{l}\mathrm{NC}:=1 \text { when the country is a neighbor- } \\
\text { ing country of the Central Asian coun- } \\
\text { tries }\end{array}$ & + & $\cdots$ \\
\hline
\end{tabular}

Three statistical models were used to estimate Eq. (8): ordinary least squares (OLS), weighted least squares (WLS), and stepwise linear regression (SLR). In the preliminary OLS regressions, it was found that the regression results for the whole of Central Asia displayed heteroscedasticity following a White test and Breusch-Pagan test, and there was a multicollinearity in the regression of Uzbekistan. Therefore, we further used Weighted Least Squares (WLS) and Stepwise Linear Regression (SLR) to overcome those problems.

First, we combined the samples for the five countries to determine the overall features of Central Asia as a region. Furthermore, to investigate the heterogeneity within the data, we employed a structural break framework. Due to the impact of the 9-11 terrorist attacks, which dramatically changed U.S. policy in Central Asia, we divided the period into several phases to identify the crucial driving factors. The regressions were implied at state-level using Ordinary Least Squares regression (OLS) and Stepwise Linear Regression (SLR).

Table 2 displays the descriptive statistics of the main explanatory variables. To examine the multiple-collinearity problem, a correlation test of the explanatory variables was conducted. Table 3 presents the results from the correlation matrix of variables, showing mostly small and modest correlations. However, two correlations stand out as being higher. The Spearman's Rho between GDP and military expenditure produced a correlation coefficient of 0.882 , while the value for the relationship between GDP and distance was 0.524 . This 
result makes intuitive sense because GDP contributes to military development, and the world's economically developed regions are generally located far from Central Asia. Table 4 presents the variance inflation factor (VIF), which is an indicator of the correlation between two or more independent variables. Common cut-off points for VIF values are generally around 5 (Studenmund and Cassidy, 1992) or lower than 10 (Hair et al., 2006). With the highest VIF value of slightly above 15 for the regression of Uzbekistan, the risk of a significant misinterpretation of the results due to multicollinearity was very high. We therefore used an SLR to filter the variables and further estimate the equation.

Table 2 The proposed variables in this study

\begin{tabular}{llcc}
\hline Variable & \multicolumn{1}{c}{ Introduction } & Mean & SD \\
\hline GDP & $\begin{array}{l}\text { The country's GDP in the year when it established diplomatic rela- } \\
\text { tions with Central Asian countries (billions of USD) }\end{array}$ & 642 & 1480 \\
PS & $=1$ when the country is a post-Soviet state & 0.23 & 0.42 \\
NATO & $=1$ when the country is a member of NATO & 0.22 & 0.42 \\
OIC & $=1$ when the country is a member of the OIC & 0.37 & 0.48 \\
ME & The country's military expenditure in the year when it established & 15.9 & 44.2 \\
DS & Geographical distance between the two capitals (km) & 3733.51 & 2269.14 \\
NC & $=1$ when the country is a neighboring country of Central Asia & 0.11 & 0.31 \\
\hline
\end{tabular}

Table 3 The correlation matrix

\begin{tabular}{|c|c|c|c|c|c|c|c|c|}
\hline & ICAN & GDP & PS & NATO & OIC & $\mathrm{ME}$ & DS & $\mathrm{NC}$ \\
\hline ICAN & 1.0000 & & & & & & & \\
\hline GDP & 0.1978 & 1.0000 & & & & & & \\
\hline PS & 0.1241 & -0.2199 & 1.0000 & & & & & \\
\hline NATO & 0.1738 & 0.3675 & -0.2369 & 1.0000 & & & & \\
\hline $\mathrm{OIC}$ & -0.1146 & -0.2974 & 0.1236 & -0.2886 & 1.0000 & & & \\
\hline $\mathrm{ME}$ & 0.1737 & 0.8824 & -0.1798 & 0.3868 & -0.2031 & 1.0000 & & \\
\hline DS & -0.0592 & 0.5240 & -0.3973 & 0.2608 & -0.4209 & 0.4907 & 1.0000 & \\
\hline $\mathrm{NC}$ & 0.1965 & -0.1202 & 0.3311 & -0.1833 & 0.3191 & -0.1058 & -0.3239 & 1.0000 \\
\hline
\end{tabular}

\section{Results}

\subsection{Evolution of Central Asia's geo-network of bilateral relations}

The degree centrality $\left(C_{D}\left(n_{i}\right)\right)$ values of the five Central Asian countries have been increasing since independence, with Kazakhstan being the highest. In 1993, there were 20 diplomatic links with Kazakhstan, but this had increased to 62 by 2013 .
Table 4 Variance inflation factor test for the OLS regression model

\begin{tabular}{lccc}
\hline & Kazakhstan & Uzbekistan & Central Asia \\
\hline GDP & 7.32 & 15.16 & 8.37 \\
PS & 2.12 & 2.33 & 1.73 \\
NATO & 1.22 & 1.50 & 1.24 \\
OIC & 1.54 & 1.71 & 1.56 \\
ME & 7.60 & 13.79 & 8.14 \\
DS & 2.24 & 2.76 & 1.73 \\
NC & 1.48 & 1.88 & 1.24 \\
Mean VIF & 3.36 & 5.59 & 3.43 \\
\hline
\end{tabular}


Uzbekistan had the second-highest degree centrality, with the number of nodes connected by diplomatic relations being 12 in 1993, increasing rapidly from 2001 to 2008, and finally being 46 by 2013. Turkmenistan's degree centrality was the lowest among the five Central Asian countries in 1993, but it increased rapidly from 1995 to 2001. By 2013, Turkmenistan had established 32 diplomatic relations. Kyrgyzstan and Tajikistan had the lowest degree centrality in 2013, with values of 23 and 22, respectively. From the perspective of degree centrality, Kazakhstan displayed the highest growth rate. Uzbekistan was the second highest, while the other three states were similar (Figure 1).
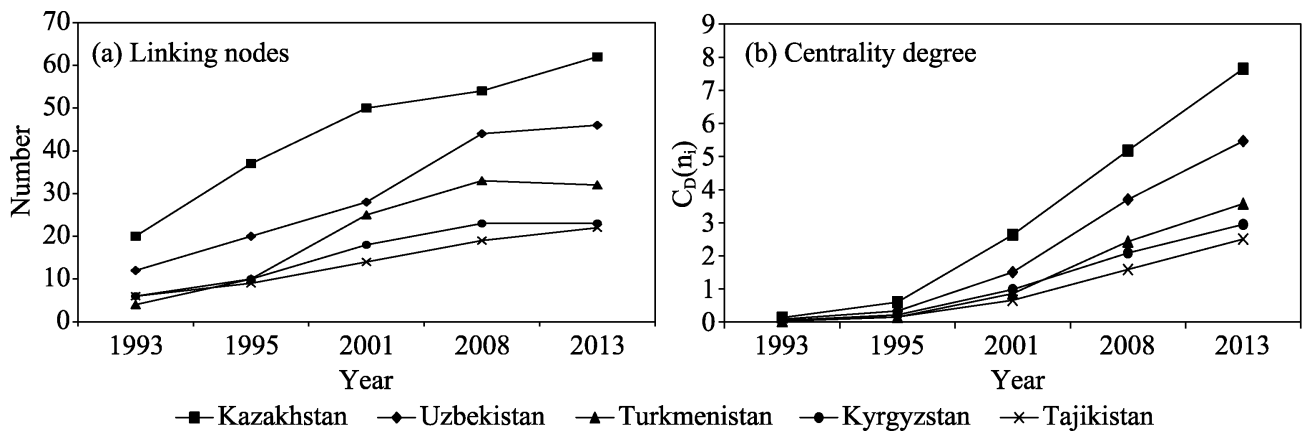

Figure 1 Degree centrality of Central Asian countries in the diplomatic relations network, 1993-2013

We identified the countries that had established diplomatic relations with the Central Asian countries. In 1993, when the geostrategies of the Central Asian countries were still unclear, it was not surprising that all of Central Asia retained close relations with Russia and other post-Soviet nations. Turkey, Iran, Pakistan, and China not only have a shared historical and cultural heritage with Central Asia, but are also critical neighboring countries. At the same time, the Central Asian countries actively or passively established formal diplomatic relations with Western countries (e.g., U.S., Germany, and Italy). In the following years, networks of diplomatic relations were rapidly established, in which post-Soviet nations, neighboring countries, and Western powers were prioritized in terms of bilateral geo-relations. After 2001, Central Asian countries gradually enhanced their relationships with other parts of the world, which was represented by closer ties with Southeast Asia.

Each country among the five "stans" had its own unique characteristics in terms of resource endowment, economic dependency with foreign countries, and security conditions, which have influenced their national geo-relations strategies. Among the Central Asian countries, Kazakhstan had the most diplomatic relations during the 20 years from 1993 to 2013. After the Soviet Union collapsed, Almaty became the location of the most significant international diplomatic community in Eurasia to the east of Moscow and west of Beijing (Gleason, 2001). By 1993, Kazakhstan had established "embassy relations" with 20 countries, including post-Soviet countries (e.g., Russia, Ukraine, Georgia, Moldova, Turkmenistan, and Uzbekistan), Western countries (e.g., the U.S., United Kingdom (U.K.), Germany, France, and Italy), Islamic countries (e.g., Turkey, Iran, and Pakistan), and eastern Asian countries (e.g., China and Japan). As of 2013, Kazakhstan had established 62 embassies inside or outside the country.

At the beginning of its independence, Uzbekistan's diplomacy focused on post-Soviet countries and Islamic countries, especially Turkey, Iran, and Pakistan to the south. By 1993, 
Uzbekistan had established diplomatic relations with the U.S., U.K., Germany, and France, with its relations with the West mainly focusing on the economy. However, there were some disputes with the U.S. over human rights, causing relational breakdowns. Between 2001 and 2008, the number of embassies established inside or outside the country grew from 28 to 44 , making it the fastest-growing country in Central Asia in terms of diplomatic relations. During this period, Uzbekistan mainly developed relations with eastern European countries and some Islamic countries. From 2008 to 2013, Uzbekistan also established embassies with Australia and the Vatican.

In 1993, Turkmenistan had only four embassies (with Russia, Kazakhstan, Iran, and Turkey) inside or outside the country. Despite Turkmenistan refusing to ally with any country or participate in military or ideological groupings, it was still recognized internationally. By 1995, bilateral relations with the U.K., U.S., France, Austria, Ukraine, and Pakistan had been established, after which the bilateral network of Turkmenistan was rapidly expanded, mainly focusing on post-Soviet countries, Islamic countries, Western countries, and other big powers (e.g., China and India). Typically, relations with the West were not harmonious, with the U.S. openly criticizing Turkmenistan's human rights record. However, given its crucial geographical location and abundant oil and gas resources, the U.S. granted Turkmenistan most-favored-nation status as a trade partner.

Kyrgyzstan first established bilateral relations with six countries, including post-Soviet countries (Russia and Kazakhstan), Islamic countries (Iran and Turkey), and Western countries (U.S. and Germany). With the dawn of the 21 st century, Kyrgyzstan has moved toward closer integration with Russia. After the Tulip Revolution of 2005, Kyrgyzstan aligned more closely with Russia, China, and its neighboring countries in Central Asia. By 2013, Kyrgyzstan had 23 embassies inside or outside the nation, slightly exceeding the number for Tajikistan.

Tajikistan had the same number of embassies as Kyrgyzstan in 1993, but with a different national distribution, i.e., replacing Kazakhstan and Germany with China and Pakistan. There was an intriguing relationship between Tajikistan and Iran, with Iran hoping to help the Tajik opposition to gain a foothold in Central Asia. Iran's intervention in Tajikistan's civil war resulted in other Central Asian countries calling for negotiation between Russia and Iran to solve the problem (Afrasiabi and Maleki, 2003). Political stability improved since the civil war ended in 1997, with the support of major foreign powers and international organizations (Gleason, 2001). The diplomatic network has steadily expanded, with a focus on Central Asian countries, post-Soviet countries, China, Islamic countries, and Western powers.

\subsection{Evolution of Central Asia's geo-network of multilateral relations}

To determine the multilateral relations, we calculated the $a_{i j}$ between the five Central Asian countries to establish a holistic IGO connection network for Central Asia (Figure 2). Using natural break classes in ArcGIS, the IGO connection strength between countries was classified into four levels: "weak" when $a_{i j}<200$, "medium weak" when $200 \leqslant a_{i j}<250$, "medium strong" when $250 \leqslant a_{i j}<300$, and "strong" when $a_{i j} \geqslant 300$. In general, the IGO connection index between Central Asia and the international community has become increasingly stronger over time. 
(a) 1993

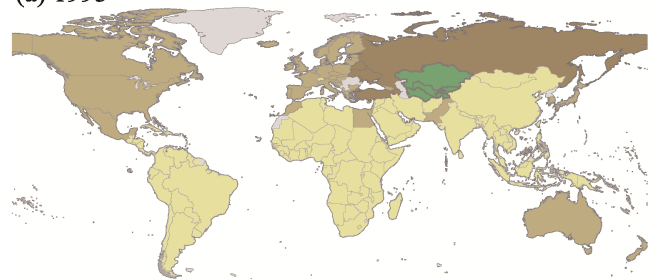

(c) 2001

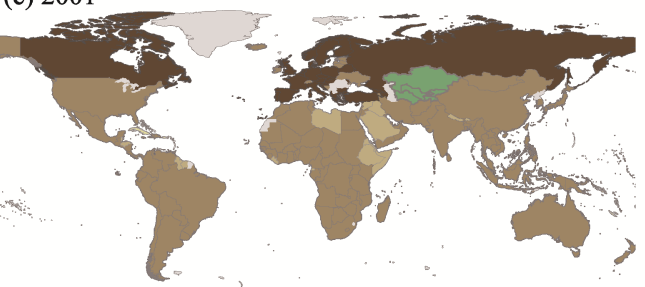

(e) 2013

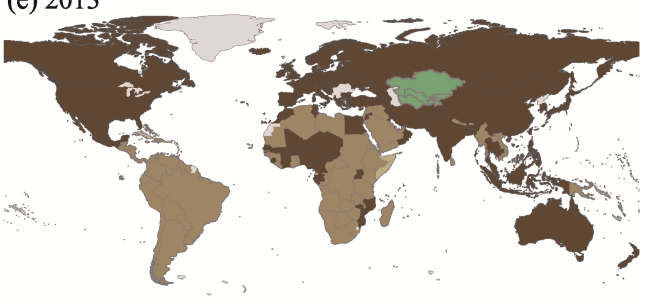

(b) 1995

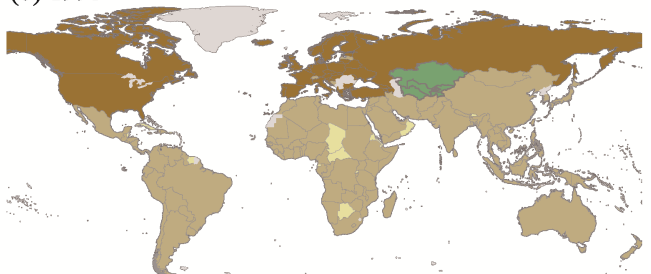

(d) 2008
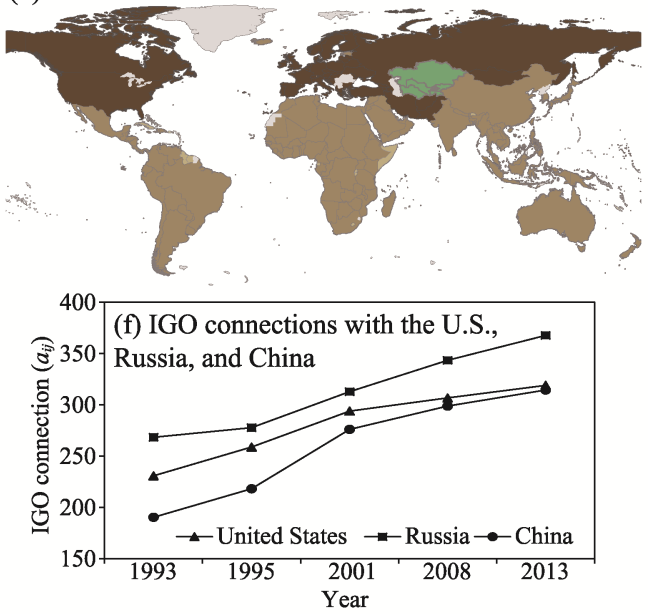

$\square$ Weak $(\mathrm{a} \leqslant 200) \square$ Medium weak $(200<\mathrm{a} \leqslant 250) \square$ Medium strong $(250<\mathrm{a} \leqslant 300) \square$ Strong $(\mathrm{a}>300) \square$ Central Asia

Figure 2 World IGO connection with Central Asia, by country, 1993-2013

At the time of their independence in 1993, seven countries reached the level of "medium weak" in their ties with Central Asia: Russia, Azerbaijan, Belarus, Armenia, Moldova, Ukraine, and Turkey. The connections with the other countries remained at the "weak" level. Central Asia at that time was most closely connected with post-Soviet countries, followed by Europe, North America, Australia, and Pakistan. All five Central Asian countries have joined the United Nations (UN), International Bank for Reconstruction and Development (IBRD), Organization for Security and Co-operation in Europe (OSCE), Economic Cooperation Organization (ECO), International Monetary Fund (IMF), Commonwealth of Independent States (CIS), European Bank for Reconstruction and Development (EBRD), and International Labor Organization (ILO), with the aim of improving their general coordination and economic cooperation. Joining these influential IGOs has enabled Central Asian countries to gain international recognition and economic aid. Central Asian countries began to embrace the Western democratic political system and develop a market economy (Pomfret, 2012), with the intention of reducing the traditional influence of Russia. The OSCE and EBRD, as the third and sixth most influential IGOs in 1993, brought Central Asian countries not only economic assistance but also European influence. The CIS, which was formed following the dissolution of the Soviet Union and consisted of nine post-Soviet countries ${ }^{1}$, has the

\footnotetext{
${ }^{1}$ In early 1993, the CIS charter proposed by Russia and others was rejected by Turkmenistan according to its "positive neutrality" as having elements of supranational maintenance. However, Turkmenistan has ratified the CIS Creation Agreement, making them "founding states of the CIS," but did not ratify the subsequent Charter that would make them members of the CIS. Turkmenistan is allowed to participate in CIS.
} 
fourth-highest weighting among the IGOs. The CIS is one of the predominant regional IGOs that influenced the structure of the geo-relation network of Central Asia at the time of its formation.

By 1995, there were 39 countries that were linked with Central Asia at the "medium strong" level, and the ties with North America and Europe had strengthened. Kazakhstan and Uzbekistan joined the International Atomic Energy Agency (IAEA), which is an IGO that seeks to promote the peaceful use of nuclear energy and restrict the development of nuclear weapons. Kazakhstan, which inherited the fourth largest nuclear arsenal in the world after the collapse of the USSR, chose to give up its nuclear weapons in exchange for political support, security guarantees, investment, and economic aid from the U.S. and other Western countries. The other IGOs that Central Asian countries joined during 1993-1995 were mainly economic organizations. Kyrgyzstan and Turkmenistan joined the Islamic Development Bank (IDB), while Kazakhstan, Uzbekistan, and Kyrgyzstan joined the Asian Development Bank (ADB), from which they received debt and economic aid to help resolve their economic problems. For example, Uzbekistan has used ADB funds to complete cooperation projects totaling more than 2.4 billion USD from 1995 to 2011 . The projects focused on four key areas: agriculture, private enterprise development, transportation, and social services, especially the protection of children and provision of primary education.

By 2001, the U.S. had opted to maintain the situation instead of intervening directly in Central Asian affairs. Central Asian countries had no other choice but to reinforce their relations with Russia to fight against extremist forces from Afghanistan and boost economic development. Thirty-two countries had "strong" ties with Central Asia, among which the links with post-Soviet countries and Europe were further strengthened. The ties with Asian, African, and American states became "medium strong," while the countries with "medium weak" and "weak" ties were mainly small and peripheral. Also by this time, Kazakhstan, Kyrgyzstan, and Tajikistan had joined the Eurasian Economic Community (EAEC), which aimed to establish a common market and achieve a unified universal tariff system inside the Union, strengthening the ties between Central Asia and Russia. Additionally, Kazakhstan, Kyrgyzstan, and Tajikistan joined the EAEC, which aimed to achieve the economic integration of its members, including Russia, Belarus, and the aforementioned three Central Asian countries. The creation of the Shanghai Cooperation Organization (SCO) was announced in June 2001 by China, Russia, and four Central Asian countries (Turkmenistan has guest attendance status in the $\mathrm{SCO}$ ). Although the SCO at that time did not influence other regional IGOs, such as the CIS and OSCE, it represented the beginning of the promotion of China's influence over Central Asia.

With the more aggressive geostrategies conducted by the U.S. after the 9-11 terrorist attacks in 2001, two military facilities were built in Uzbekistan and Kyrgyzstan. The average $a_{i j}$ of Central Asia and the U.S. increased from 293.9 in 2001 to 306.8 in 2008, with a 4.37\% growth rate. However, with the impact of the color revolutions, Central Asian countries immediately strengthened ties with Russia. The $a_{i j}$ increased from 312.8 to 343.4 during the period of 2001 to 2008, and the growth rate of $a_{i j}$ was $9.77 \%$. The Collective Security Treaty Organization (CSTO), as a military alliance of six post-Soviet countries, was the main IGO that Central Asian countries joined during this period. 
After the 2008 global financial crisis, the membership of IGOs was relatively stable among the Central Asian countries, but they became connected more closely with countries and regions such as China $\left(a_{i j}=314.4,2013\right)$, Southeast Asia (average $\left.a_{i j}=298.38,2013\right)$, Australia $\left(a_{i j}=310.79,2013\right)$, and some parts of Africa. At the same time, Central Asia did not relinquish its ties with the West. In December 2010, Kazakhstan hosted the OSCE Summit of Leaders.

Comparing Central Asia's IGO connections with the U.S., Russia, and China, we found that Russia's ties with Central Asia have always been the strongest, followed by the U.S., with China having the weakest connections. However, with the increasing influence of China in international affairs, China's IGO connection index with Central Asia has recently had a higher growth rate than that of the U.S., with the connection level almost reaching the U.S. level by 2013 .

\subsection{Comparison and analysis of Central Asia's geo-networks}

We were interested in the influence of Central Asian countries on the regional geo-network. By comparing the degree centrality of Central Asian countries in the diplomatic relations and IGO connection networks (Figure 3), it was apparent that the centrality of the five Central Asian countries in the diplomatic relations network was quite different (standard deviation of $C^{\prime}{ }_{D}\left(n_{i}\right)$ was 1.03), while the centrality in the IGO network was similar (standard deviation of $C_{I G O}^{\prime}\left(n_{i}\right)$ was 0.04$)$. This was because the weights of the IGOs that Central Asian countries have joined successfully leveraged differences in quantity (although the number-deviation was still the leading cause of differences), which means the weaker countries tended to use multilateral diplomacy to make up for their deficiency in bilateral diplomacy. Kazakhstan had the highest degree centrality in the diplomatic network, but not in the IGO network. To our surprise, Tajikistan had the lowest degree centrality in the diplomatic network but the highest degree centrality in the IGO network (in 2013). To explain these phenomena, we counted the number of IGOs that Central Asian countries were members of and calculated the average weights of these organizations (Table 5). The results showed that Kazakhstan still had the largest number of IGO memberships, having joined 51 IGOs by 2013. This was followed by Kyrgyzstan, with 45 memberships, Tajikistan with 42, and Uzbekistan with 40. Turkmenistan had the fewest memberships, with only 35 . However, in

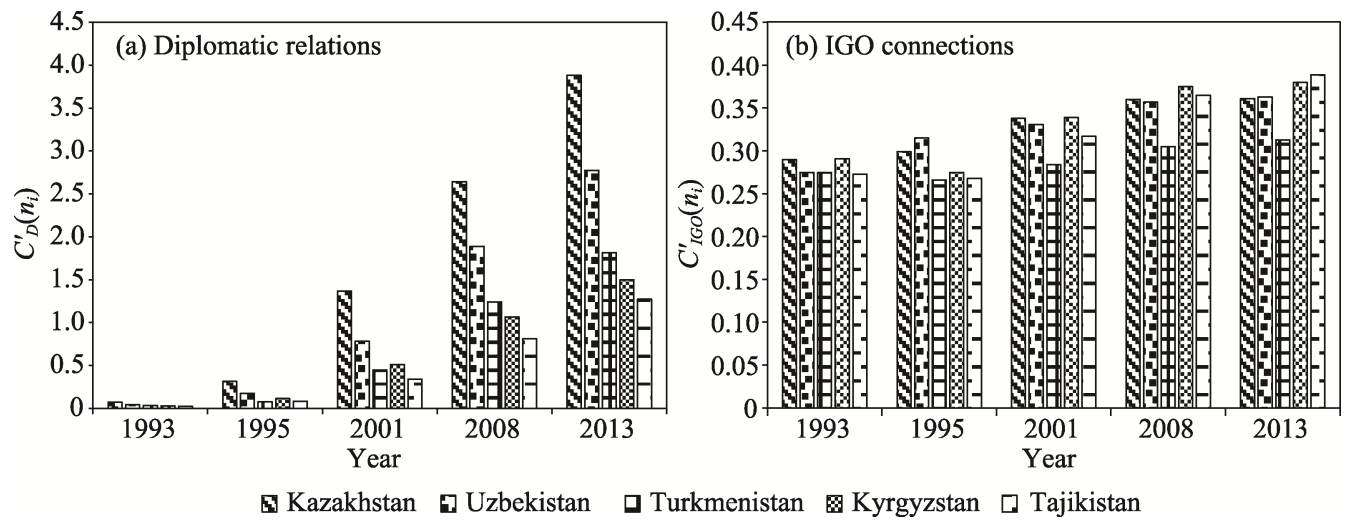

Figure 3 Degree centrality of Central Asian countries in diplomatic relations and IGO connection networks, 1993-2013 
Table 5 Description of the IGO connection network for Central Asian countries in 2013

\begin{tabular}{lccccc}
\hline & Kazakhstan & Kyrgyzstan & Tajikistan & Uzbekistan & Turkmenistan \\
\hline IGO membership & 51 & 45 & 42 & 40 & 35 \\
Average weight & 7.82 & 9.26 & 10.18 & 9.40 & 8.79 \\
Centrality & 386.30 & 399.73 & 402.02 & 372.71 & 303.85 \\
\hline
\end{tabular}

terms of the average weight of IGOs, Tajikistan had the highest number, while Kazakhstan had the lowest, indicating that Kazakhstan attached great importance to the expansion of its membership of IGOs. At the same time, the other Central Asian countries were better at increasing their influence in geo-relation networks by joining influential IGOs.

In the CONCOR procedure, we divided the IGO network into 2-3 blocks (Figure 4), from which we could determine which block Central Asia belonged to, i.e., its power dependence. The results revealed that, in the IGO network of 1993, Central Asia's

(a) 1993

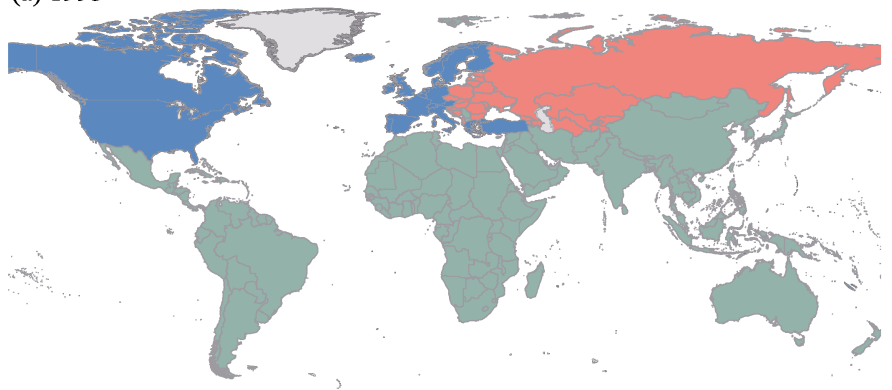

(b) 2013

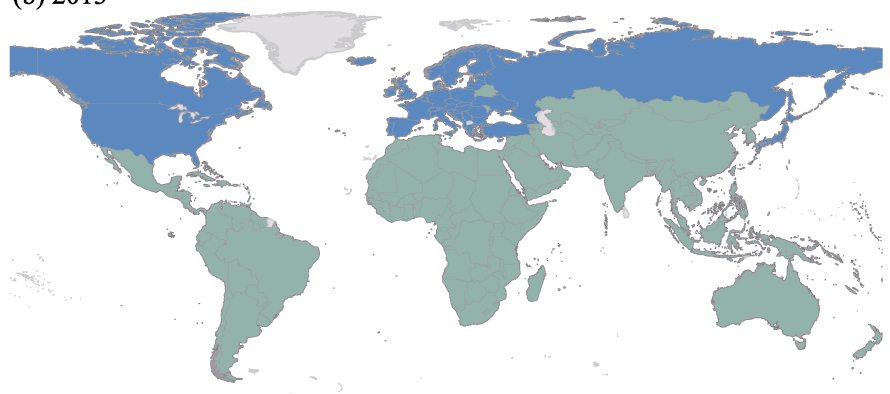

Third World block $\quad$ Former Soviet Union block

West block

Figure 4 The blocks of world IGO networks as determined by CONCOR

geo-relation network was

connected most closely with the post-Soviet countries. The images for 2013 were almost identical, with Central Asia having the most similarity with the Third World. With the end of the cold war, the influence of the international organizations created by the post-Soviet states declined, and the east-west confrontation no longer existed. Although the Central Asian countries have joined many national and regional IGOs since their independence, it is still a small region located geographically far from the Western world and has limited international influence. The promotional influence of the IGOs created by emerging countries (e.g., the SCO) has played an important role in their evolutionary process. Therefore, it was not surprising that Central Asia was positioned in the block representing the Third World.

\subsection{Factors shaping Central Asia's geopolitical network}

The regression results for the whole of Central Asia obtained from the OLS, SLR, and WLS analyses were similar. Due to the heteroscedasticity among the variables, only the results from the WLS are discussed here. Kazakhstan's OLS and SLR regression results were similar. However, because of the multicollinearity in the regression for Uzbekistan, there were large differences between the OLS and SLR results. Therefore, we only considered the SLR 
results for Kazakhstan and Uzbekistan.

We first considered the results of the WLS model for the whole of Central Asia during the period of 1993-2013 (column 3, Table 6). We found that economic power (GDP), identity as post-Soviet states (PS), membership of NATO, geographical distance (DS), and neighboring countries (NC) were all significant and correctly signed. These findings supported hypotheses 1, 2a, 2b, 5a, and 5b. In contrast, military expense (ME) was significant, but the sign was contrary to the expectation predicted in hypothesis 4 .

Absolute economic power (GDP) had a positive influence on a country's importance degree in the geo-relation network of Central Asian countries, with a 1\% rise in GDP increasing the length of time for which an embassy was established from or to Central Asian countries by $0.16 \%$. This indicates that economic power was a crucial motive for establishing bilateral relations with Central Asian countries during the period studied (hypothesis 1). Membership of post-Soviet IGOs and NATO (hypotheses $2 \mathrm{a}$ and $2 \mathrm{~b}$ ) had a slight or medium positive significant effect on the establishment of the geo-relations of Central Asian countries. This result suggests that one of the characteristics of Central Asia's geo-relations was "balance," with no apparent tendency toward the West or East in the 20-year study period. However, membership of the OIC was not supported in the regression, indicating that the Islamic world had no apparent attraction to Central Asia in the formation of its geo-relation network. The geographical variables (distance (DS) and neighboring countries (NC)) were also positive and significant. As land-locked countries, the Central Asian nations attach great importance to their relations with neighboring countries. Distance plays an essential role in the bilateral relations of Central Asian countries, whose regional geostrategies have focused on Eurasia. It was confusing to find that the coefficient for the military expenses (ME) index indicated a decreasing relationship between the military power of one country and its degree of importance in the geo-relation network. We found that a $1 \%$ increase in military expenditure was associated with a $0.1 \%$ decrease in the length of time for which an embassy was established. Thus, we found no evidence to support hypothesis 4 . This result was counter to common sense and requires further discussion. We speculate that there might have been opposing forces operating in different periods, which might have influenced the results of the regression for all samples from 1993 to 2013.

To investigate whether the driving forces of the Central Asian geo-relation networks changed in character over the period in question, we divided our data into four periods (1995, 2001, 2008 as the breaking points). Due to the limited number of samples after 2008, no estimation was attempted for that period. The other procedures applied are listed in columns 4,5 , and 6 of Table 6 , indicating relatively sharp contrasts.

For the period 1993 to 1995, post-Soviet states (PS), Organization of the Islamic Conference (OIC), military expense (ME), and neighboring countries (NC) were significant determinants of Central Asian geo-relations. Among these significant determinants, the identity as post-Soviet states (PS) and Organization of the Islamic Conference (OIC) were the two most supportive factors, with coefficients of about 0.05 . In this period, it was found that the establishment of the geo-relation network in Central Asia had a strong path dependence, through which Central Asian countries tended to establish bilateral relations with post-Soviet and Islamic countries. Unlike over longer periods, military expenses (ME) played a positive role in the network, with a correlation coefficient of 0.02 . At the same time, neighboring countries were prioritized. 


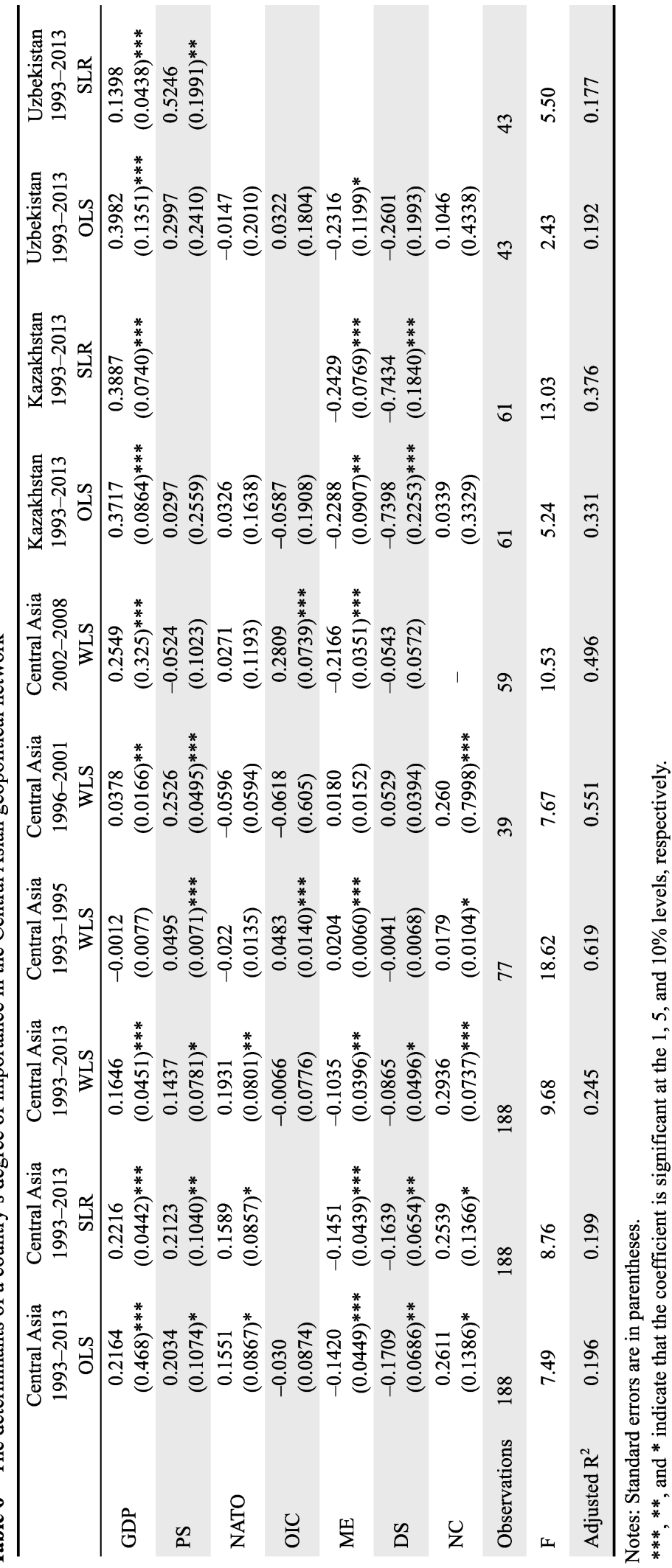


During 1996 to 2001, economic power (GDP), post-Soviet states (PS), and neighboring countries (NC) were significant and positive factors. Neighboring countries (NC) was the most powerful driving force, with a coefficient of 0.26 indicating that it played a critical role in the geo-relation network of Central Asia. The coefficient for the identity as post-Soviet states (PS) was 0.25 , indicating that the former Soviet bloc still had a large influence on the geopolitical network in central Asia. Economic power (GDP) had a coefficient of 0.04, which suggests that it had only a slight influence on the geo-relations of the Central Asian countries. The results suggest that the Central Asian countries began to establish geo-relations with economic powers, while also enhancing relations with both post-soviet and neighboring countries.

For the period 2002 to 2008, Organization of the Islamic Conference (OIC) replaced membership of post-Soviet states (PS) in importance as a variable, while economic power (GDP) and military expense (ME) were also significant. Organization of the Islamic Conference (OIC) had a higher coefficient (0.28) than that of economic power $(0.25)$, indicating that Central Asian countries attached importance to the development of relations with economic powers and Islamic countries, and that historical and cultural proximity played a prominent role in the Central Asia geo-relation network. As the Central Asian countries established diplomatic relations with relatively small countries, the geo-relation network has been greatly extended, resulting in military power having a negative effect on the network. For the period 2008 to 2013, due to the limited sample numbers of Central Asian countries establishing diplomatic relations, the regression was not significant. There were no apparent driving forces for the establishment of geo-relations in this period.

In summary, the geopolitical networks of Central Asian countries have focused on the neighboring region, Western countries, economic power, and post-Soviet Union states during the 20 years covered in this study. In terms of the regional strategy, there was a precise "tripartite balance" tendency that focused on the surrounding regions, the West, and the former Soviet Union. For their other interests, Central Asian countries have pursued geographical relationships with economic powers. Central Asia's driving force for building a geopolitical network has differed during the various different periods studied here. In the early period, it focused on strengthening ties with the post-Soviet Union, Islamic countries, and neighboring countries, while later it focused more on strengthening ties with economic powers (Table 7).

Table 7 Determinants of a country's degree of importance in the Central Asian geopolitical network

\begin{tabular}{ccl}
\hline Region/country & Period & Driving factors (sorted by coefficient value, from largest to smallest) \\
\hline Central Asia & $1993-2013$ & NC, NATO, GDP, PS, DS (-) \\
Central Asia & $1993-1995$ & PS, OIC, ME, NC \\
Central Asia & $1996-2001$ & NC, PS, GDP \\
Central Asia & $2002-2008$ & OIC, GDP, ME (-) \\
Kazakhstan & $1993-2013$ & GDP, ME (-), DS (-) \\
Uzbekistan & $1993-2013$ & PS, GDP \\
\hline
\end{tabular}

Various theories and the visualization of the network suggest that government strategies have different characteristics among the five Central Asian countries, with consideration of their individual internal and external conditions. By comparing the results for the subsamples in columns 8 and 10 of Table 6 (only suitable for Kazakhstan and Uzbekistan due to sample constraints), we found that economic power (GDP) was significant and correctly 
signed for both countries. This implies that economic power played an essential role in the geo-relation networks of both countries. At the same time, Kazakhstan was driven by the candidate country's military expense (ME) and distance (DS), while Uzbekistan gave more attention to the post-Soviet states (PS). It was significant that the coefficient of the index of military expenses (ME) and distance (DS) were both negative in terms of their degree of importance in the geo-relation network of Kazakhstan. It was found that a $1 \%$ increase in the military expense caused a $0.24 \%$ decrease in the length of time for which an embassy was established. Moreover, a $1 \%$ increase in distance (DS) was associated with a $0.74 \%$ decrease in the length of time for which an embassy was established. Kazakhstan tended to establish geo-relations with countries with stronger economic power, weaker military power, and a location further from the Eurasian heartland. Due to the positive effects of economic power and post-Soviet states identity, Uzbekistan persistently established geo-relations with more durable economic powers and post-Soviet countries, with the latter factor being the most important in the geo-relation network of the country.

History has confirmed these empirical results. Despite the former President Nazarbayev emphasizing the development of balanced diplomatic relations with the world, it was clear that special attention was given to the relationship with Western countries and two neighboring countries, Russia and China, in his report "A Strategy for the Development of Kazakhstan as a Sovereign State". Kazakhstan has established strategic alliances in politics, economics, and security with Russia, while at the same time attempting to develop a relationship with the U.S. in terms of security, economics, and international status. Additionally, Kazakhstan has repeatedly emphasized the need to develop friendly and good-neighborly relations with China and the more extensive Asia-Pacific region (Ambrosio and Lange, 2014). Europe is another region in which Kazakhstan hopes to increase its international role by actively participating in European affairs.

The accession of Kazakhstan to the European Union has always been a national goal. In contrast, after 20 years of development, Uzbekistan's bilateral diplomacy is still centered on the post-Soviet countries, China, Islamic countries, and Western countries. Additionally, Uzbekistan has been reaching out to its eastern and western Asian friends under its "multi-vectoral" policy (Spechler and Spechler, 2010).

Due to the lack of empirical results, history can also provide some details regarding the other three countries. Turkmenistan has declared "positive neutrality" as its foreign policy (Anceschi, 2010), in which its bilateral geo-relations stem primarily from perceived threats and benefits to the regime's stability rather than from rational economic calculations (Anceschi, 2009). There is a special status for the country's bilateral relations with Russia and other post-Soviet countries. With regard to the country's relationship with Iran, the former President Niyazov stated that, "We have a 1700-kilometer border with Iran. We have no choice but to cooperate with Iran." The commitment to develop a road and rail link between the two countries and a gas pipeline to carry gas to Europe has further enhanced the bilateral relationship with Iran. Relations with Turkey have also developed rapidly for traditional, ethnic, and cultural reasons, with cooperation between the two countries focusing on the economy. Kyrgyzstan has sought good geopolitical relations with the big powers. As the first president of Kyrgyzstan stated, "Small countries need big friends." Kyrgyzstan has used its unique location to bargain with powers from different blocs. However, although Kyrgyzstan 
has pursued a balanced diplomacy, the balancing effect has been limited because of its weak power in international relations (Huskey, 2008). Tajikistan's geopolitical strategy is an "alliance with Russia". Due to its geographical location, Tajikistan has been threatened by regional terrorism for a long time. Joining the SCO will undoubtedly enable it to use the power of China and Russia to ensure national security best practices. Furthermore, Tajikistan is the only country that borders Central Asia, China, South Asia, and West Asia, and the country therefore has the ability to connect the four major regions and become a regional hub in Central Asia.

\section{Conclusions and discussion}

In this study, we first conducted a social network analysis to evaluate the construction and evolutionary process of the Central Asian geo-relation network. In the bilateral diplomatic relations network, the Central Asian countries were found to have gradually established a diplomatic network, and their presence in the network grew over time. Kazakhstan had the highest degree centrality and also had the highest growth rate. Uzbekistan was ranked second, while the other three states were relatively peripheral in the network. Since the early years of their independence, the Central Asian countries have focused on developing relations with the post-Soviet countries, neighboring countries that share a similar cultural and historical heritage, and Western countries. Despite the expansion of their diplomatic relations network, the key areas of the geostrategies, including post-Soviet countries, Europe, the U.S., Islamic countries, and neighboring countries have always been underscored. The evolution of the network indicates that Central Asian countries strengthened their ties with the post-Soviet countries, gradually moved towards the West, but significantly enhanced their ties with China and other parts of the world after 2008.

The network of multilateral relations was constructed according to membership of IGOs. The analysis results revealed that Kazakhstan had the largest number of IGO memberships and joined 51 IGOs in 2013. However, when considering the average weight of those IGOs, Tajikistan was the highest, while Kazakhstan was the lowest. This suggests that the geostrategic approaches adopted by the five countries were different. Kazakhstan attached great importance to joining IGOs, while other Central Asian countries increased their influence in geo-relation networks by joining more influential IGOs. With its higher strategic level, Kazakhstan was found to be more willing to establish and expand its geographic network as a "big country in Central Asia," while the other countries were more willing to rely on large international communities to realize their national interests.

The empirical research showed that economic power, political properties and groupings, cultural proximity, military power, and geographical factors were all driving factors in the process by which Central Asia built its geo-relation network. When we examined the differences over time, we found that identity as post-Soviet states, membership of the OIC, military expenses, and neighboring countries were the main factors and driving forces for the establishment of a geo-relation network before 1995. The driving factors from 1996 to 2001 were different, with economic power, membership of post-Soviet IGOs, and neighboring countries being more important, while the driving forces of economic power were still relatively small. After 2011, economic power, religion, and military power were the most important determinants. In general, the geo-relation network of the Central Asian countries was 
primarily driven by political and cultural factors, and then later focused on the development of relations with neighboring countries. In the 21 st century, economic power and cultural and religious proximity became the dominant driving forces.

For the two biggest Central Asian countries, Kazakhstan and Uzbekistan, the driving factors in establishing their geo-relations included economic power. Kazakhstan tended to establish geo-relations with countries with stronger economic power, weaker military power, and a location far from the Eurasian heartland. Uzbekistan tended to establish geo-relations with stronger economic powers and post-Soviet countries, with the latter factor being the most important in the country's geo-relation network.

We believe that the way to realize national interests is to enhance the power of the state in the network, for which different countries will adopt different geostrategies according to their situation. Central Asia, as a 'new-born' region with limited power in the international social network, is dependent on external powers because they eagerly need to be recognized internationally and ensure their national interests by balancing the forces of all parties. Therefore, to increase their influence in geo-relation networks, Kazakhstan adopted the strategy of expanding bilateral and multilateral relations, while other smaller countries tended to become members of influential IGOs. At different stages, national geostrategies have different priorities.

This study represented a preliminary exploration of the formation and development of the geopolitical network in Central Asia, and provided a valuable insight into the geo-relations of the geostrategic intersections among the great powers, supporting the study of the geopolitics of the Central Asia region. However, this study was not able to closely combine every networking result with an associated detailed history due to the weaknesses of quantitative research. Through empirical research, this study was able to determine the driving forces for the building of new diplomatic relations, but it ignored the maintenance, reinforcement, and weakening of the geopolitical relations. More extensive and profound studies are therefore needed to develop deeper insights into geo-relations.

\section{References}

Afrasiabi K, Maleki A, 2003. Iran's foreign policy after 11 September. The Brown Journal of World Affairs, 9(2): $255-265$.

Ambrosio T, Lange W, 2014. Mapping Kazakhstan's geopolitical code: An analysis of Nazarbayev's presidential addresses, 1997-2014. Eurasian Geography and Economics, 55(5): 537-559.

Anceschi L, 2009. Turkmenistan's Foreign Policy: Positive Neutrality and the Consolidation of the Turkmen Regime. Abingdon: Routledge.

Anceschi L, 2010. Integrating domestic politics and foreign policy making: The cases of Turkmenistan and Uzbekistan. Central Asian Survey, 29(2): 143-158.

Bayne N, Woolcock S, 2011. The New Economic Diplomacy: Decision-making and Negotiation in International Economic Relations. Farnham, Burlington: Ashgate Publishing, Ltd.

Cooley A, 2008. US bases and democratization in Central Asia. Orbis, 52(1): 65-90.

Cooley A, 2012. Great Games, Local Rules: The New Power Contest in Central Asia. New York: Oxford University Press.

de Haas M, 2016. Security policy and developments in Central Asia: Security documents compared with security challenges. The Journal of Slavic Military Studies, 29(2): 203-226.

Gleason G, 2001. Foreign policy and domestic reform in Central Asia. Central Asian Survey, 20(2): 167-182.

Gross J-A, 1992. Muslims in Central Asia: Expressions of Identity and Change. Durham, London: Duke University Press. 
Hafner-Burton E, Kahler M, Montgomery A, 2009. Network analysis for international relations. International Organization, 63(3): 559-592.

Hair J, Black W, Babin B et al., 2010. Multivariate Data Analysis: A Global Perspective. Upper Saddle River. London: Pearson Education.

Hämmerli A, Gattiker R, Weyermann R, 2006. Conflict and cooperation in an actors' network of Chechnya based on event data. Journal of Conflict Resolution, 50(2): 159-175.

Henrikson A K, 2002. Distance and foreign policy: A political geography approach. International Political Science Review, 23(4): 437-466.

Hopkirk P, 1992. The Great Game: The Struggle for Empire in Central Asia. New York: Kondasana International.

$\mathrm{Hu}$ H, Wang S, Ge Y, 2018. Regional differences of border geo-cities in China and the surrounding countries. Journal of Geographical Sciences, 28(3): 351-366.

Huskey E, 2008. Foreign policy in a vulnerable state: Kyrgyzstan as military entrepot between the great powers. China \& Eurasia Forum Quarterly, 6: 5-18.

Huntington S, 1996. The Clash of Civilizations and the Remaking of World Order. New York: Simon and Schuster.

Jing C, Tao H, Jiang T, et al., 2020. Population, urbanization and economic scenarios over the Belt and Road region under the Shared Socioeconomic Pathways. Journal of Geographical Sciences, 30(1): 68-84.

Kinne B, 2013. IGO membership, network convergence, and credible signaling in militarized disputes. Journal of Peace Research, 50(6): 659-676.

Kubicek P, 1997. Regionalism, nationalism and realpolitik in Central Asia. Europe-Asia Studies, 49(4): $637-655$.

Li T, Long D, 2014. Geopolitical position of Central Asian countries and geopolitical strategy of China. Progress in Geography, 33(3): 303-314. (in Chinese)

Liu H, FANG C, Miao Y et al., 2018. Spatio-temporal evolution of population and urbanization in the countries along the Belt and Road 1950-2050. Journal of Geographical Sciences, 28(7): 919-936.

Maoz Z, Terris L G, Kuperman R D et al., 2005. International relations: A network approach. In: Mintz A, Russett B (eds.). New Directions for International Relations: Confronting the Method-of-Analysis Problem. Lanham: Lexington Books, 5-64.

Minghi, Julian V, 1963. Boundary studies in political geography. Annals of the Association of American Geographers, 53(3): 407-428.

Nye J, 2008. Public diplomacy and soft power. The ANNALS of the American Academy of Political and Social Science, 616(1): 94-109.

Pirro E, 2015. Great power foreign relations in Central Asia: Competition, cooperation and congruence. In: Sussex M, Kanet R (eds.). Russia, Eurasia and the New Geopolitics of Energy: Confrontation and Consolidation. London: Palgrave Macmillan UK, 112-136.

Pomfret R, 2012. Central Asia after two decades of independence. In: Roland G (ed.). Economies in Transition: The Long-Run View. London: Palgrave Macmillan UK, 400-429.

Sandschneider E, 2002. China's diplomatic relations with the states of Europe. The China Quarterly, 169: 33-44.

Schweitzer F, Fagiolo G, Sornette D et al., 2009. Economic networks: The new challenges. Science, 325(5939): 422-425.

Smith D, White D, 1992. Structure and dynamics of the global economy: Network analysis of international trade 1965-1980. Social Forces, 70(4): 857-893.

Song T, Lu D, Liang Y, 2017. The evolution of great powers' geostrategy during their rise: A case study of the United States and its enlightenment to China. Geographical Research, 36(2): 215-225. (in Chinese)

Spechler D R, Spechler M, 2010. The foreign policy of Uzbekistan: Sources, objectives and outcomes: 1991-2009. Central Asian Survey, 29(2): 159-170.

Studenmund A, Cassidy H, 1992. Using Econometrics: A Practical Guide. Boston: Addison-Wesley Educational Publishers.

Wasserman S, Faust K, 1994. Social Network Analysis: Methods and Applications. Cambridge: Cambridge University Press.

Yang Y, Liu Y, Jin F, 2015. Study on energy cooperation between China and the Central Asia and Russia under the view of energy geopolitics. Geographical Research, 34(2): 213-224. (in Chinese)

Zawahri N A, Mitchell S M, 2011. Fragmented governance of international rivers: Negotiating bilateral versus multilateral treaties. International Studies Quarterly, 55(3): 835-858.

Zhang J, Chen Y, Li Z, 2018. Assessment of efficiency and potentiality of agricultural resources in Central Asia. Journal of Geographical Sciences, 28(9): 1329-1340. 